\title{
Preschool Children Preferences on their School Environment
}

\author{
Nurul Nadiah Sahimi \\ Faculty of Education and Social Science, \\ Universiti Tun Abdul Razak \\ nadiahns@yahoo.com
}

\begin{abstract}
Children and adults have different views and preferences about the environment around them. Digital camera pictures offer a tangible documentation and representations of children's perception and preferences regarding their school environment. This study is to identify children's photography selection and preferences on the school environment, both indoors and outdoors. This study was conducted on 19 preschoolers $(n=19)$ of age 4 and 5 using the project based approach. The children were given a digital camera and were asked to take pictures of things in their school environment that they really liked. Their photographs were analyzed to see their overall preferences about their school environment.
\end{abstract}

Keywords: children, photographs, preferences, school environment

eISSN 2514-751X @ 2017 The Authors. Published for AMER ABRA by e-International Publishing House, Ltd., UK.. This is an open access article under the CC BY-NC-ND license (http://creativecommons.org/licenses/by-ncnd/4.0/). Peer-review under responsibility of AMER (Association of Malaysian Environment-Behaviour Researchers), ABRA (Association of Behavioural Researchers on Asians) and cE-Bs (Centre for EnvironmentBehaviour Studies), Faculty of Architecture, Planning \& Surveying, Universiti Teknologi MARA, Malaysia.

https://doi.org/10.21834/aje-bs.v2i3.192 


\subsection{Introduction}

Understanding young children's perspectives about their environment is important and should be taken into consideration in research as well as in practice. By knowing what young children think, adults; especially parents and teachers can understand these young children's emotions, needs, interests and preferences much better. This could probably offer a more meaningful learning experience to the children by acknowledging and providing materials and experiences that are significant to their interest. However, it is a question of how far adults are willing to consider children's perspectives, and how adults, especially teachers take into account young children's perspectives. In a report by Cook \& Hess (2007), Scott (2000) suggested that there is a large gulf between adult observation about a child's understandings of a situation and the child's own perceptions. This is consistent with DeMarie (2001) which shows that what the preschool children notice, photograph and say about the field trip is not exactly the same as how adults expected it. Thus, it is agreed that adults can not actually see the world from a child's perspective (Cook \& Hess, 2007) and children's perspectives are recognized as separate to and different from those of adults. However, since the need to understand young children's perspectives have been emphasized into practice, children are now given the openness and opportunities to make choices and thus teachers should provide a rich experience to each child as a necessary foundation for the child to be able to tell others about their own perspectives (Samuelsson, 2004). One method that has gain popularity among practitioners and researchers is through the use of cameras by young children.

Children's photographs are indeed a salient and visible documentation of their personal views about the environment. This is because the lens of the camera is subject to a focal point where it captures and documents the viewer's specific point of interest. Besides, photography creates an immediate sense of being there, where children responses are centred around feelings (as expressed by the subjects in their photographs) and factual information about places represented in the photographs (Schiller \& Tillett, 2004). It has been realized that through photography, children have described themselves not just as artists, but also as thinkers and decision-makers. When children capture pictures of the environment, they are in charge of their own decisions; they are experts of their own interest while providing evidence (Einarsdottir, 2005). Through photography, children capture pictures of what they want, and at the same time making choices on things that are most important to them or things that make an impression on them (Cook \& Hess, 2007; Einarsdottir, 2005). However, with respect to the child's perspective, it is important to bear in mind that children's expression of meaning is always taking place in a certain situation and a specific context, based on his or her earlier experiences and capacity to express himself or herself (Samuelsson, 2004). Thus, it might also important for adults to offer a focused field of knowledge, despite listening and allowing children to express their views and opinion in order to understand their perspectives of the environment. Hence, this study is to identify children's photography selection on the school environment, both indoors and 
outdoors and to investigate their preferences for their school environment and the objects around them.

\subsection{Literature Review}

Young children are no longer excluded from the existence of photographs, and young children these days are in fact regularly exposed to many types of photographs, either commercial photographs or educational photographs. Children are first exposed to pictures and photographs when parents start reading story books to their infants or perhaps showing photographs of the family members to them for the first time. Pictures and photographs serve as symbols of representing our world and they often share the physical resemblance with their referents. It is important for someone to understand that photographs are artifacts that serve as a symbol that represents something other than itself (DeLoache, 1991), which are surprisingly easy for children to relate to. However, to understand pictures, one must represent the picture and its referent at the same time to be able to draw an inference from one to the other (DeLoache, Pierroutsakos \& Troseth, 1996; Salsa \& Peralta DeMendoza, 2007). According to De Loache (1991), when someone looks at a picture, he will focus on the representation not the picture as an object. Therefore, although very young children might not appreciate photographs as much as adults, photographs and pictures are found to be much easier for young children to understand and to relate with the real object (see DeLoache, 1991).

Nowadays, many practitioners and researchers prefer to use cameras as part of projects conducted with young children. This is because the digital technology can be a powerful and useful tool in assisting young children with projects although it can be utilized in various ways for various purposes. The key feature of this project is deliberately focused on finding answers to questions about a topic posed either by the children, the teacher, or the teacher working with the children (Helm \& Katz, 2001). Besides, it allows children to engage in discussion on pervious experiences and knowledge related to the topic, gathering and recording new data, taking measurement, and so forth and it encourages children to identify subtopics of special interest to them and to accept responsibility for particular types of tasks that will contribute to the overall investigation (Katz \& Chard, 2000). One section of the project approach is the utilization of technology, which can improve the quality of learning experiences in the classroom and one way to utilize the use of technology is through the use of cameras by children, for them to explore and see the world around them. With the emerging use of technology in the classroom, the use of cameras is no longer a huge challenge for many young children, especially those who live in the urban area, as the camera is widely used by many families on various occasions and for various events. Besides, with the development of modern equipment, it has been easy for beginners to take photographs, and most children who are offered the camera tend to show great enthusiasm for taking pictures. The development of good single use camera, and now 
digital technology, have recently made photography more accessible to children than ever before (Thomas, Davison \& Sharples, 2001).

Several researches have shown the use of camera among young children and photographs taken by them, through activities such as field trips, self exploration and direct engagement with the environment. For example, in a study by DeMarie (2001), children were taken to a zoo on a field trip and each child was given a disposable camera and was asked to take pictures that he or she thinks are important about the field trip. This is to find out children's perspectives about their school field trips and also to see if the time, expense and anxiety that teachers feel when organizing long trips were worth it. In another study by DeMarie \& Ethridge (2006) preschoolers were given cameras during school session, to show their families what happened at their centres during the day the children were there through the photographs taken. The results show that when young children were given cameras as part of their project activities, they tend to show more details about the classroom than when they were just asked questions without any photographs. This shows that the camera can be a very useful for children to work on as part of their projects, as it can benefit both children and adults in many ways.

\subsection{Methodology}

\subsection{Participants}

This study involved a random sample of, 6 four-years-old and 13 five-years-old children $(n=$ 19), with a total of five males and fourteen female. These children attend their preschool and kindergarten at Twinkle Tots Day Care Centre, Wangsamaju, Kuala Lumpur. All of these children are at the center 5 days a week from $8.00 \mathrm{am}$ to $1.00 \mathrm{pm}$. Most of the participants have used cameras before, based on an informal interview when the camera was first introduced.

\subsection{Procedure}

Children were first engaged in two discussions (during circle time) about cameras and the things that they like the most in the school. After each discussion, they were given cameras for them to be familiar with the tool. Once the children were comfortable handling the camera, they were asked to take pictures of things that they like the most in the school. Each child was given approximately 45 to 60 minutes to handle the camera and they were consistently reminded of the question when they handle the cameras. During the photography session, the children were interviewed on some of the photographs to ensure they were taking pictures of the things they liked in school. A total of $n=747$ pictures were analyzed and pictures are divided into two categories; outdoors and indoors to find out their preferences in their environment. 


\subsection{Results and Discussions}

As the children were given the liberty to take pictures of anything and anywhere they liked in the school, most of the children tended to take snapshots of both indoor and outdoor. Only 2 children (4 years old) took photos only of the outdoors and 1 child of the same age took photos only of the indoors. One of the children, Alia, explained about her preference for taking photos outdoors when asked whether she wanted to take photos of her classroom.

\section{"No. Alia like it outside. I like trees, flowers and more!"}

Looking at the overall children's photographs, results show that there are more photos of the outdoors compared to the indoors. A total of 747 (70\%) from 1078 photographs were compiled and analyzed. A total of 331 photos were not included in the analysis due to very blur and dark images, due to poor handling of the camera. From the total of 747 photos, a total of $285(38 \%)$ photos were taken indoors, $313(42 \%)$ were photos taken outdoors and $149(20 \%)$ were portraits (see Table 1). The portraits were separated from the outdoor and indoor categorization because they do not reflect any preferences towards the indoor or outdoor environment. Overall, more photos were taken outdoors compared to indoor and portraits, which shows that children do have preferences of the outdoors, and not just indoors; where they spend most of their time throughout the day.

Table 1: Total children's photographs on indoor, outdoor and portraits

\begin{tabular}{lcccc}
\hline & Indoor & Outdoor & Portraits & Total \\
\hline 4 and 5 years old & 285 & 313 & 149 & 747 \\
& $(38 \%)$ & $(42 \%)$ & $(20 \%)$ & $(100 \%)$ \\
\hline
\end{tabular}

Table 2: Total photographs taken by 4 and 5 years old children

\begin{tabular}{cccc}
\hline & $\mathbf{4}$ years old & $\mathbf{5}$ years old & Total \\
\hline No. of Photos & 275 & 472 & 747 \\
& $(37 \%)$ & $(63)$ & $(100 \%)$ \\
\hline
\end{tabular}

From the overall total of 747 photographs compiled, a total of $275(37 \%)$ photographs were taken by the 4-years-old $(n=6)$ and a total of $472(63 \%)$ photographs were taken by the 5 years old $(n=13)$ (see Table 2). The huge difference in the number of photographs taken by these two groups of children is because of the lack of participation from four other 4-years-old, which probably was due to lack of interest or they were engaged in other activities which they preferred, when the camera was offered to them. Table 3 shows that out of the 275 photographs taken by the 4-years-old, $27(10 \%)$ of them were taken indoors and179 (65\%) were taken outdoors and $69(25 \%)$ were pictures of people (portraits). From the total of 472 photographs taken by the 5 years old, $258(55 \%)$ were photos of indoors, $134(28 \%)$ outdoors and $80(17 \%)$ photographs of people. Indoor photos which were taken 
included indoor activity areas, decorations, self-owned materials and classroom materials. Outdoor photos included outdoor areas, outdoor decorations, nature and outdoor toys.

Table 3 below shows that the 4-years-old children tend to take more pictures of the outdoor and people compared to the 5-years-old. Only one of the 4 years old children took pictures only in the classroom (indoor) only and none outside. This is probably because of the classroom location, which is located on the ground floor of the building and the classroom entrance leads straight to the outdoor area, which is easily accessible for the children. Since the classroom provides easy access to the outdoors, children are allowed to move in and out of the classroom during their activity time (such as to pluck leaves during art activities). On the other hand, results show that the 5-years-old children tend to take more photos of the indoors compared to the 4-years-old. This is also probably due to the location of the classroom, which is located on the first floor of the building. Children in this classroom are given more indoor activities as the outdoor environment is not easily accessible and they are only allowed to be outside only at a certain time of day. These 5years-old usually spend more of their time indoors then outdoors compared to the 4 years old and therefore, that is the possible reason why their photograph selections focus more of the indoor environment.

Table 3: Comparisons of 4 and 5-year-old children's photographs on indoor, outdoor and portraits

\begin{tabular}{lcccc}
\hline & Indoor & Outdoor & Portraits & Total \\
\hline 4 years old & 27 & 179 & 69 & 275 \\
& $(10 \%)$ & $(65 \%)$ & $(25 \%)$ & $(100 \%)$ \\
\hline 5 years old & 258 & 134 & 80 & 472 \\
& $(55 \%)$ & $(28 \%)$ & $(17 \%)$ & $(100 \%)$ \\
\hline
\end{tabular}

Looking at the overall photographs, children of both ages are capable of taking wide, close-up and detailed snapshots, using the 'zoom control', which actually illustrate a particular activity area as well as specific objects such as a particular flower.

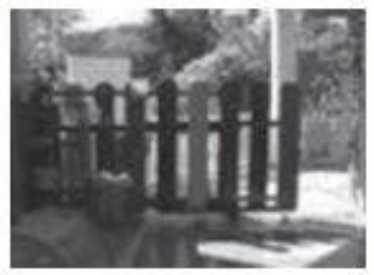

(Picture 1)

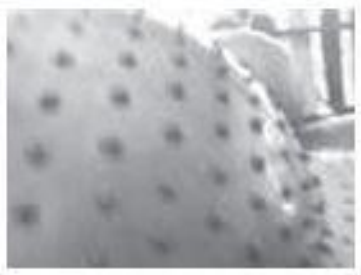

(Picture 2)

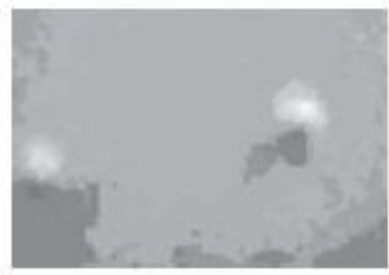

(Picture 3)

For example, with a wide snap shot, we can see that the child has chosen to take a photo of the ball area (picture 1) which is located outside the classroom. With a close-up 
snapshot (picture 2) the child is focusing on a more specific object, which is the ball that they like to play with and, with a detail snap shot (picture 3), the child has focused on a very specific area of the entire ball, which are the spikes. With the ability to produce such photos, it shows that children are able to actually show the specific location and things that they like in the school.

Below are some of the pictures taken by the children age 4 and 5 :

4 years old:
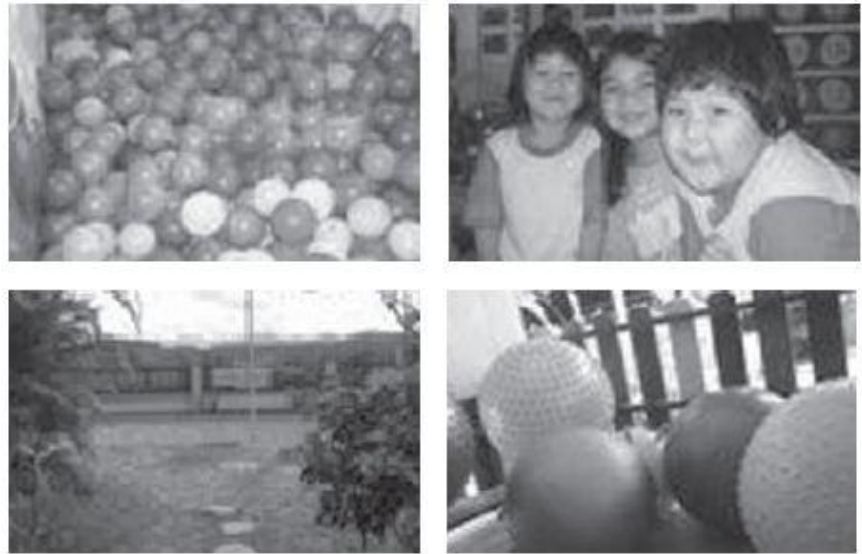

5 years old:
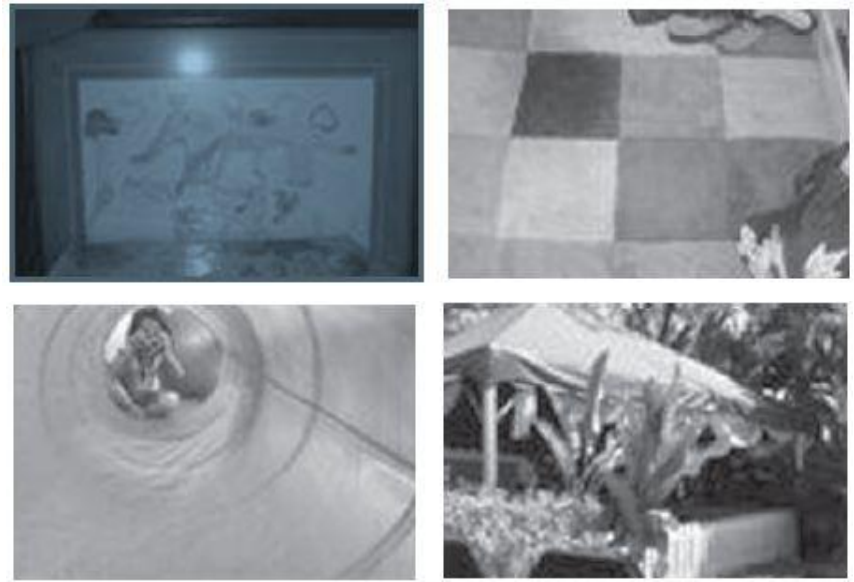
During the process of the project, each child was interviewed on a randomly picked photo to ensure that they were taking photos of things they liked in school. Each child did mention why he or she took that picture and some explained what they really liked about that picture. Based on these interviews, it is clear that children did take photos of the things that they liked, and they were more selective in their photographs when they were given a specific question. Below are some of the interviews on their photos.

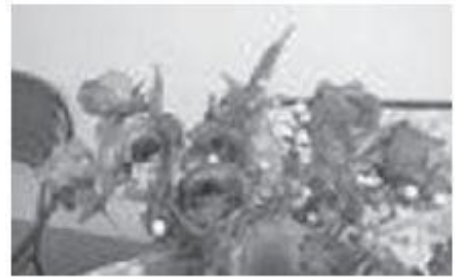

Picture 1

(4 years old male)

"Nice flowers!"

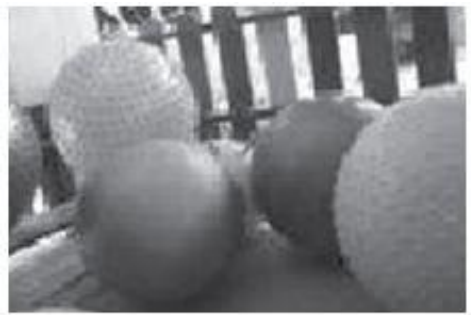

Picture 3

(4 years old female)

"Uuuuu..... like big balls. Doing! Doing!"

(making bouncing actions)

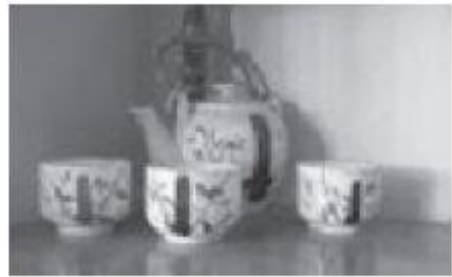

Picture 2

(5 years old female)

"I like this. I feel like cooking."

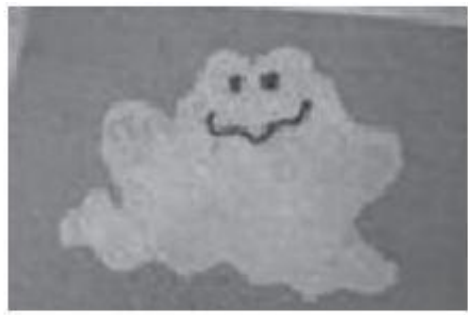

Picture 4

(5 years old female)

"I like pink. I like it. Nice"

\subsection{Discussions}

Photography can be a valuable experience for each and every child, as it allows the child to seek, decide and discover things and the environment around them, besides giving them a chance to develop their skills in photography. Each child was obviously excited when given the chance to handle the camera and as he or she moves around the school, the child tends to discuss, share and give opinion about the pictures taken by others. These children are also capable handling the camera and many are capable of manipulating some parts of the camera carefully and successfully, such as the zoom control, shutter release and the display button, which could help produce quality photos and the LCD screen tend to give 
children a sense of reassurance of the photos taken. Based on the above findings, it shows that young children prefer to take more pictures of the outdoors compared to the indoors. However, due to the different location of both classrooms there is a big difference for each age group's preferences towards the environment. The 4-year-olds are found to take more photos of the outdoors while the 5-year-olds are found to take more photos of the indoors. This is probably because the classroom of the younger group is located on the ground level of the building while the 5-year-olds' classroom is located on the first floor of the building. So, the outdoor environment is more easily accessible for the 4 years old compared to the 5 years old. This gives the 4-year-olds the opportunity to interact more frequently with the outdoor environment. Therefore, it is recommended that the location of each classroom should be on the same ground level with easy access to the outdoor environment, as this will give children a richer learning experience. Besides, it is also recommended that if the classroom does not have easy access to the outdoor environment, teachers should consider giving children frequent breaks to be outdoors.

\section{Acknowledgement}

The author wishes to acknowledge the cooperation and participation of the children and staff of the preschool and kindergarten which were involved in this study. She also acknowledges the support provided by Universiti Tun Abdul Razak (UNIRAZAK).

\section{References}

Arterberry, M.E., Milburn, M.M., Loza, H.L. \& Willert, A.S. (2001). Retrieval of episodic Information From Memory: Comparisons Among 3- and 4-Year-Olds, 7- and 8-Year-Olds, and Adults. Journal of Cognition and Development, 2(3), 283-305.

Carter, C.C. (2006). Digital Photography and Journals in a Kindergarten-First-Grade Classroom: Toward Meaningful Technology Integration in Early Childhood Education. Early Education and Development, 17(3), 347371.

Cook, T. \& Hess, E. (2007). What the Camera Sees and from Whose Perspective: Fun Methodologies for Engaging Children in Enlightening Adults. Childhood, 14(1).

DeLoache, J.S. (1991). Symbolic Functioning in Very Young Children: Understanding of Pictures and Models. Child Development, 62, 736-752.

DeLoache, J.S., Pierroutsakos, S.L. \& Uttal, D.H. (1996). The Origins of Pictorial Competence. Psychological Science, 12(4), 114-118.

DeMarie, D. (2001). A Trip to the Zoo: Children's Words and Photographs. Early Childhood Research and Practice. 3(1). 
DeMarie, D. \& Ethridge, E.A. (2006). Children's Images of Preschool: The Power of Photography. Young Children, 61(1)101-104. Wilson Education Abstracts.

Deocampo, J. A. \& Hudson, J.A. (2003). Reinstatement of 2-year-olds' Event Memory Using Photographs. Memory, 11(1), 13-25.

Einarsdottir, J. (2005). Playschool in Pictures: Children's Photographs as a Research Method. Early Child Development and Care, 175(6), 523-541.

Farrar, M.J. \& Goodman, G.S. (1992). Developmental Changes in Event Memory. Child Development, 63, 173187.

Fasoli, L. (2003). Reading Photographs of Young Children: Looking at Practices. Contemporary Issues in Early Childhood, 4(1), 32-47.

Helm, J. H., \& Katz, L. G. (2001). Young Investigators: The Project Approach in the Early Years. New York: Teachers College Press.

Hudson, J.A., Fivush, R. \& Kuebli, J. (1992). Scripts and Episodes: The Development of Event Memory. Applied Cognitive Psychology, 2, 483-505.

Katz, L. G., \& Chard, S. C. (2000). Engaging Children's Minds: The Project Approach (2nd ed.). Stamford, CT: JAI Press.

Matthews, J. (2006). Very Young Children's Development in Moviemaking. Mind, Culture and Activity, 13(2), 130156.

Mecklenbrauker, S., Hupbach, A. \& Wippich, W. (2001). What Color is the Car? Implicit Memory For Color Information in Children. The Quarterly Journal of Experimental Psychology, 54A (4), 1069-1086.

Pickering, S.J. (2001). The Development of Visuo-Spatial Working Memory. Memory, 9 (4/5/6), 423-432.

Price, D.W.W. \& Goodman, G.S. (1990). Visiting the Wizard: Children's Memory for a Recurring Event. Child Development, 61, 664-680.

Salsa, A.M. \& Peralta de Mendoza, O. (2007). Routes to Symbolization: Intentionality and Correspondence in Early Understanding of Pictures. Journal of Cognition and Development. 8(1), 79-92.

Samuelsson, I.P. (2004). How Do Children Tell Us about Their Childhoods? Early Childhood Research \& Practice. $6(1)$.

Schiller, J. \& Tillett, B. (2004). Using Digital Images with Young Children: Challenges of Integration. Early Child Development and Care, 174(4), 401-414.

Sheffield, E.G. \& Hudson, J.A. (2006). You Must Remember This: Effects of Video and Photograph Reminders on 18-Month-Olds' Event Memory. Journal of Cognitive and Development, 7(1), 73-93.

Simcock, G. \& Hayne, H. (2003). Age Relate Changes in Verbal and Nonverbal Memory During Early Childhood. Developmental Psychology, 39(5), 815-814. 